UDK 528.73

\title{
ANALYTICAL AND DIGITAL PHOTOGRAMMETRIC GEODATA PRODUCTION SYSTEMS (A COMPARISON TEST)
}

\author{
Birutė Ruzgiené $\dot{ }^{1}$ Edita Alekniené $\dot{e}^{2}$ \\ Dept of Geodesy and Cadastre, Vilnius Gediminas Technical University, \\ Sauletekio al.11, LT-10223 Vilnius, Lithuania \\ E-mail: ${ }^{1}$ Birute.Ruzgiene@ap.vgtu.lt, ${ }^{2}$ Edita.Alekniene@ap.vgtu.lt
}

Received 0102 2007, accepted 30032007

\begin{abstract}
Up-to-date mapping technologies are in the middle of transition from analytical to digital. The usage of new methods and technologies implies the desire to increase mapping capability. Despite that, analytical and digital methods may be used simultaneously, thus getting more efficient results. The research objective is to present some aspects of functionality of both digital and analytical photogrammetric mapping approaches in generating 3D geodata. The experimental results show which of the two methods could lead to a more flexible mapping production in consideration of the following criteria: accuracy, flexibility, time and cost. The main result of investigations shows, that the orthophoto generation is successfully using fully automatic systems. The digital terrain models created by two technologies are almost the same due to time-consuming. Therefore more time is required for the Digital Photogrammetric System when the terrain is rougher. Despite the fact that digital photogrammetric mapping technology drastically develops, there is no doubt that analytical photogrammetry is still a significant production system for large-scale mapping. The results demonstrate that there is not too much difference in accuracy between the analytical and the digital $14 \mu \mathrm{m}$ pixel size images processing. The interpretation capability of experimental test area in the Digital Photogrammetric System was more complicated as it was by the analytical plotter. Two systems integrations have been foreseen. Digital terrain model obtained by the analytical plotter can be transferred to digital mapping system for orthophoto generation.
\end{abstract}

Keywords: aerial images, analytical photogrammetry, feature extraction, digital photogrammetric system, digital terrain model, orthophoto production.

\section{Introduction}

Since 1990 the transition from analogue and analytical photogrammetric mapping technologies to digital started. Current mapping technologies are in the transition from the analytical to digital ones. The turn towards the digital technologies was caused by a desire to increase mapping efficiency through automation of mapping procedures. New digital image processing methods have a potential to improve the photogrammetric production cost-performance relation.

Despite the above-mentioned fact, the digital photogrammetric technologies cannot be completely replaced. The analytical photogrammetric technologies considering many practical reasons could be used. For example, digital aerial triangulation needs more time than processing by the analytical plotter or simply it will not work at all under such conditions as [1]:

- in dense urban areas,

- at large height difference in the photographed area,

- in a heavily vegetated terrain,

- $\quad$ in different aerial photography seasons etc.

Really, only the digital production of orthophotos currently turns to the broadest usage. However, with the help of analytical photogrammetric systems only mapping tasks which meet difficulties in automation can be solved efficiently. For example, feature extraction is still interactive manual or semi-automatic process.

The evolutionary transition from the analytical to digital photogrammetric mapping technologies integrating both should be more acceptable.

Implementing methods of digital photogrammetry, the research has to be carried out comparing two systems in image orientation, aerial triangulation, digital terrain model generation, stereo feature extraction and orthophotos production, investigating such criteria as systems flexibility, production time, accuracy and costs consideration.

The decision how two mapping systems could be used together leads to a more flexible map production, reduces costs and time considering project deadline requirements and increasing demand for digital data and for topographic maps from aerial photographs.

Digital photogrammetric technologies have not completely replaced analytical photogrammetric technologies. The older technologies are still used and are very important for such a strategy: introducing new technology to implement old and new technologies parallel for getting the highest productivity. 
The objectives of research is to present the main aspects of functionality from both digital and analytical photogrammetric mapping approaches in generating 3D geodata, to evaluate the two systems by experiments and to investigate how to integrate them for achieving a maximum efficiency for photogrammetric production.

\section{Methodology}

The availability of photogrammetric software has made the analytical plotting operations a common procedure. The modern stereo (also digital) plotters are designed on the basis of analytical plotting techniques. Analytical photogrammetry is to establish the relationship between image space and object space by analogue photographs to describe mathematical calculation of points coordinates based on camera calibration parameters, measured images coordinates and ground control points.

In an analytical plotter, automatically driving the measuring mark to different points and controlling by operator, the parallaxes can be computed creating the stereo model. Thus relationship between the image and control points coordinates has been established automatically. Collected 3D data can be plotted at any scale.

The operations (measurement of points image coordinates $x$ and $y$ in stereo pair, movement for definition of points location) in an analytical plotter are performed by computer. Digital encoders allow to measure coordinates. These coordinates are stored in the computer. Servomotors, receiving signals from the controlling computer, can move the photographs for defining the point locations. Hardware, control electronics and application software are the main parts of an analytical plotter.

The schematic diagram of components and operation of an analytical plotter could be found in [2].

The main goal of digital photogrammetry is to automatise photogrammetric processes using only digital images (Fig 1) [1, 3].

Digital photogrammetric systems have a potential for processing image data from different sources and the

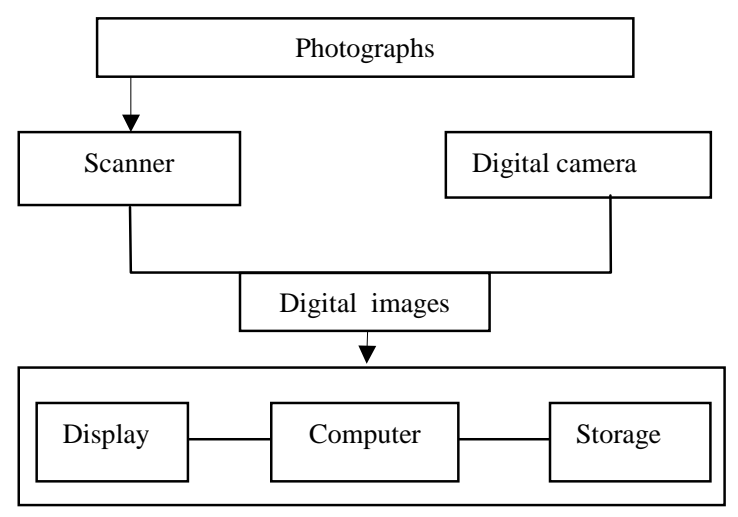

Fig 1. Schematic diagram of digital photogrammetric components results can be applied in geographical information systems.

Using a digital photogrammetric system some problems appears in data acquisition, storage capacity and automation. Digital images are obtained directly using digital cameras or indirectly by scanning analogue photographs. Up to now most data are scanned by aerial photographs.

The scanners are very sensitive instruments and some errors may appear due to proper calibration, environmental, maintenance conditions and image processing software. The high scan resolution is required for a better interpretability and higher accuracy. Because of that data acquisition becomes more expensive. The cost of scanners or its services leads to increasing the initial cost of digital photogrammetric production.

The orthophotography production is an automated process, therefore there is a little cost variation in any country. The orthophotographic mapping, when aerial photography is taken with analogue aerial camera, is based on costs per image [4]: scanning - €10; aerial triangulation - $€ 20$; generation of digital elevation model - €90; orthophoto generation - €25.

Line (stereoscopic) mapping on stereo plotters is a labour-consuming process. Depending on density of topographic details in a photograph, the plotting time could vary from $10 \mathrm{~h}$ per model in open territory to $100 \mathrm{~h}$ in urban areas. For stereo plotting, labour prices are very different in different countries and vary from $€ 15$ to $€ 30$ per hour. If the average features restitution time is $50 \mathrm{~h}$ per model and labour costs $€ 15$ per $h$, the stereo mapping cost for model is €750.

The resolution of aerial images, the accuracy of determining the point position and the cost of photogrammetric production depend on the image scale.

\section{Experiments}

The goal of experiments was to investigate and optimise the workflow in two systems - analytical and digital for production of geodata.

Data input. Analogical images at a scale of 1:6000 with $62 \%$ forward and $33 \%$ sideward overlap covering the eastern-northern part of Vilnius were used for experimental measurements. The diapositives were scanned with pixel size $14 \mu \mathrm{m}$ by photogrammetric scanner Vexell Ultra Scan, getting digital images in TIF format. For digital processing system images were converted to $B M P$ format with size of $16862 \times 16861$ pixels.

Analogous diapositives covering the same area have been used for the analytical system for measuring by an analytical plotter.

Aerial cameras $R M K T O P$ calibration parameters and control points were used for interior and exterior orientation. Camera focal length $c=153,6 \mathrm{~mm}$, flying height $H=910 \mathrm{~m}$.

Hardware and software. The measurements were done by an analytical plotter Zeiss Stereoplotter PLANICOMP P3 - of excellent working condition, with 
the possible image size of $240 \times 240 \mathrm{~mm}$, magnification (zoom) 5-20x, Aristo digitizer active area $594 \times 420 \mathrm{~mm}$, black measuring mark, cursor 36-72 P, P33 - digitising table. The PLANICOMP additionally equipped with CCD cameras at Photogrammetry Institute of Bonn University. For images orientation software $P$ - $C A P$ Vers. 6.2.1 has been used.

The digital images processing was performed by a Digital Photogrammetric station DDPS [5]. This software was developed within the framework of a cooperative project between the Surfaces Laboratory, Dept of Geomatics, University of Liege (supervising by Prof J. P. Donnay), Belgium and the Institute of Geodesy and Cartography (IGiK), Dept of Photogrammetry (supervising by Prof R. Kaczynski), Poland. DDPS is a complete and integrated photogrammetric package with user-friendly interface and easy for usage.

Aerial triangulation was performed using analogous images for measuring image coordinates by the analytical plotter Leica SD2000, and bundle block adjustment was carried out with software NLHBUNT. The accuracy after block adjustment is expressed by units of sigma naught $\sigma_{0}$ - the variance estimator. Analytical sigma naught $\sigma_{0}=8,28 \mu \mathrm{m}$ in image coordinate system was received and $0,050 \mathrm{~m}$ in the terrain. The accuracy of ground control points position $-0,030 \mathrm{~m}$ [6].

A complete photogrammetric treatment was possible with Digital Photogrammetric Software by a realised workflow (Fig 2).

\begin{tabular}{|c|c|}
\hline \multicolumn{2}{|c|}{ INNER ORIENTATION } \\
\hline Pixel coordinates & $\rightarrow$ Photo coordinates \\
\hline Calibration Certificate & Left/Right Images \\
\hline \multicolumn{2}{|c|}{$\downarrow$} \\
\hline \multicolumn{2}{|c|}{ EXTERIOR ORIENTATION } \\
\hline RELATIVE ORIENTATION & ABSOLUTE ORIENTATION \\
\hline Photo $\rightarrow$ Model Coordinates & Model $\rightarrow$ Ground Coordinates \\
\hline Homologous Points & Control Points \\
\hline \multicolumn{2}{|l|}{$\downarrow$} \\
\hline EPIPOLAR RESAMPLING & \multirow{2}{*}{ IMAGE MATCHING } \\
\hline \multirow{2}{*}{$\begin{array}{l}\text { Determination of the } \\
\text { Bounding Box }\end{array}$} & \\
\hline & $\downarrow$ \\
\hline & GENERATION OF DEM \\
\hline \multirow{2}{*}{$\begin{array}{l}\text { VRML MODEL } \\
\text { GENERATION }\end{array}$} & $\downarrow$ \\
\hline & ORTHORECTIFICATION \\
\hline
\end{tabular}

Fig 2. General workflow in DDPS
Practical results. Fig 3 shows the graphical representation of data plotted by a analytical plotter, Fig 4 - generated data on the Digital Photogrammetric station.

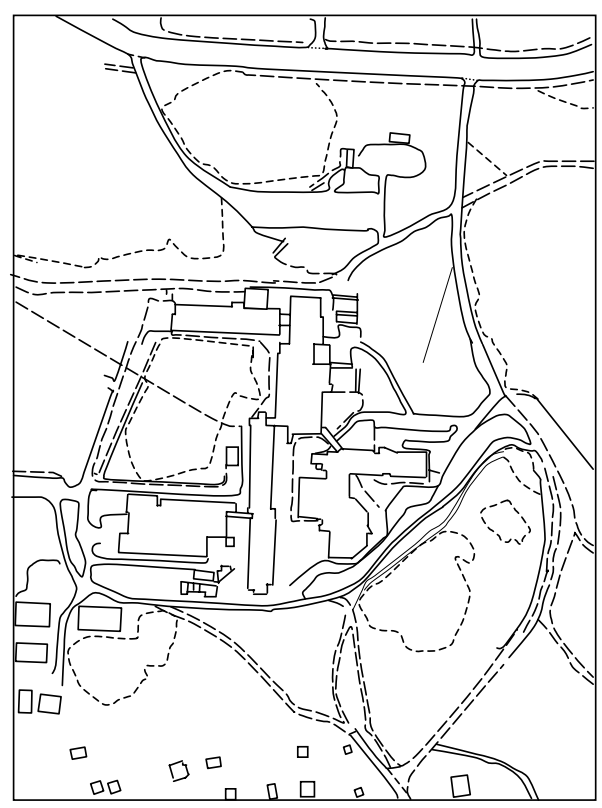

Fig 3. Fragment of stereoscopic plotting

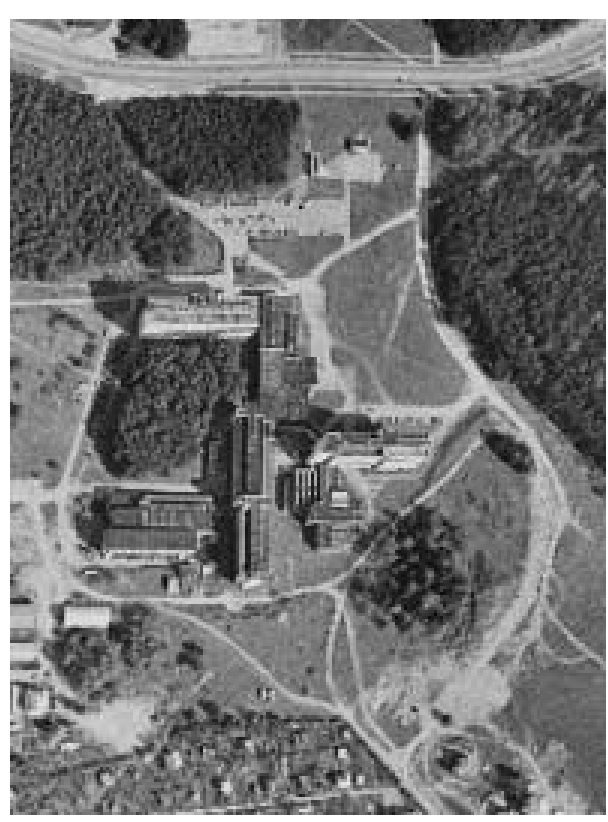

Fig 4. Fragment of generated orthophoto

Analysis of comparison results. The comparison of two systems (digital and analytical) results was performed and evaluated regarding the flexibility, time consuming, accuracy and costs.

The mapping processes by an analytical plotter require high-skilled operators and mostly operations require an intensive labour, especially when collecting point elevations. 
The digital system is more flexible because of automation of most procedures. The operator's work is easy by DDPS system than by an analytical plotter. Furthermore, interpretation capabilities are more effective when stereo viewing an analytical plotter even when digital image resolution is $14 \mu \mathrm{m}$.

The inner orientation of the analytical system requires more time than that of the DDPS. Furthermore, an advantage of the digital system is that if the inner orientation is performed, its parameters are stored. It means that in case of re-measuring the inner orientation does not need repeating.

The labour time for creating the Digital Terrain Model (DTM) depends of terrain types: flat or hilly, area covered by vegetations (for example, forests), urban or unbuilt territory. The DTM generation in digital systems for complicated areas offers a large number of wrong measurements and needs for extensive interactive corrections. In such a situation an analytical plotter is an advantage.

In test area (Fig 4) the terrain is on average open and not too much roughed. Therefore, automatic DTM have been processed very well - only $2 \%$ of blunders were detected. The time consuming processing by DDPS was about 2,5 times less than it was performed by an analytical system.

The geometric accuracy of photogrammetric processes performed with both systems was evaluated. The influence on accuracy when changing image resolution was investigated as well, processing images on DDPS images with $14 \mu \mathrm{m}$ also with $28 \mu \mathrm{m}$ image resolution. The above-mentioned changed the have change accuracy not significantly, considering that required results satisfy the requirements of reference geodata base creation at a scale of 1:1000 or 1:2000.

The root mean square errors RMSE were calculated from the differences of ground control points and tie points coordinates using analytical and digital systems. Results of the experiments show that the accuracy of geodata collected from two systems are approx at the same level (planimetrical positional RMSE - 0,10 m, heights $-0,15 \mathrm{~m})$. However, it has been defined that automatic DTM is a little lower in accuracy than manually collected by an analytical plotter.

During many trials, it was realized that it is significant to create denser grid for digital elevation model generation.

Cost consideration. An image scale of 1:6000 provides a resolution and a positional restitution of $6 \mathrm{~cm}$. Scanned at $14 \mu \mathrm{m}$, it is suitable for generation of $8 \mathrm{~cm}$ ground pixel orthophotos. This scale permits the mapping the feature details. A photo covers $1,4 \times 1,4 \mathrm{~km}=$ $1,96 \mathrm{~km}^{2}$ (frame size $23 \times 23 \mathrm{~cm}$ ). A model covers an area of $1,47 \mathrm{~km}^{2}$ (when longitudinal overlap is $62 \%$, and side overlap $33 \%$ - model size $0,38 l \times 0,67 l ; l=23 \mathrm{~cm}$ ).

The investigated area $\left(1,47 \mathrm{~km}^{2}\right)$ can be produced into orthophoto at $€ 145$ (cf paragraph 3).

Average time for stereoscopic feature extraction - of $25 \mathrm{~h}$ for that model, with labour cost $€ 10$ per $\mathrm{h}$, the mapping cost for this area is $€ 250$.
The received results demonstrate that orthophoto production is a much cheaper than stereoscopic mapping (approx 2 times). Line maps have advantages for usage in GIS. However, not all features need to be stereoplotted.

In digital photogrammetric systems before using aerial photography they must be scanned with a high resolution, for getting digital images with a proper accuracy and good interpretability. Therefore geodata acquisition becomes more expensive. However, the time saved through automation will reduce the scanning cost.

Photogrammetric hardware of the analytical systems is quite expensive (PLANICOMP P3 costs about $€ 30$ 000). Also, digital systems hardware requires a great capacity of storage devices, high quality monitors for image display and powerful processors. Software for image processing and hardware needs maintenance. All these factors influence the production costs.

The study of the systems evaluation in financial aspects in not complete and needs for further investigations.

\section{Conclusions}

The investigation has shown that digital technologies include without any doubt the possibility to generate new products and they can replace the traditional analytical production. However, using digital and analytical mapping technology it is very useful to join both creating hybrid workflow in a photogrammetric process:

- feature extraction on the DDPS comparing with stereo plotting by an analytical plotter is not very desirable;

- only digital orthophoto production is fully reliable in a digital photogrammetric mapping.

Extending capabilities for the future the analytical and digital systems should be run together:

- digital systems are recommended for open and flat terrain and in orthophotographic mapping;

- analytical approach is more relevant for urban terrain covered by vegetation and mountainous areas.

Constructing the hybrid photogrammetric mapping system, parameters of aerial triangulation, vector data from the analytical plotter can be successfully realised on the digital photogrammetric system for a successive processing.

\section{References}

1. Manual of Photogrammetry (ed by Chris McGlone). 5th edition. American Society for Photogrammetry and Remote Sensing, USA, 2004. $1151 \mathrm{p}$.

2. WOLF, PAUL R.; DEWITT, BON A. Elements of Photogrammetry with Application in GIS. 3rd edition. USA McGraw-Hill, 2000. 608 p.

3. BUTOWTT, J.; KACZYŃSKI, R. Fotogrametria. Warszawa: Wojskowa Akademia Techniczna, 2003. 375 p. (in Polish).

4. KONECNY, G. Geoinformation: Remote Sensing, Photogrammetry and Geographical Information Systems. London and New York: Taylor and Francis, 2003. 248 p.

5. Didactic and digital photogrammetric software (DDPS). User's guide. Donnay J-P., Kaczynski R. Dept of 
Geomatics, University of Liege (Belgium) Institute of Geodesy and Cartography (IGiK), Dept of Photogrammetry, Warszawa, Poland, 2005. $71 \mathrm{p}$.

6. The georeferenced data bases of Vilnius city and creation of an aerial triangulation by photogrammetric method (Vilniaus miesto georeferencinès duomenu bazès ir aerofototrianguliacijos sudarymas fotogrametriniu būdu). Mokslo darbo ataskaita. Vadovas A. alnierukas. VGTU Geodezijos institutas, 1997. 70 p.

Birutė RUZGIENE். Assoc Prof, Doctor. Vilnius Gediminas Technical University, Dept of Geodesy and Cadastre, Saulètekio al. 11, LT-10223 Vilnius, Lithuania. $\mathrm{Ph}+3705274$ 4703, Fax +370 5274 4705,

e-mail: birute.ruzgiene@ap.vgtu.lt.

A graduate of Vilnius Civil Engineering Institute (engineer of geodesy, 1968). Doctor (Vilnius Gediminas Technical University, 1999). Research training at Moscow Institute of Geodesy, Aerosurveying and Cartography (1986), at Norway AO Fjellanger Widerøe (1995), at Warsaw Institute of Geodesy and Cartography (1998), at Photogrammetry Institute of Bonn University $(2000,2005)$. Author of more than 30 research papers.

Research interests: digital photogrammetric mapping, image interpretation, features extraction from remote sensing data.
Edita ALEKNIENE். Master of science. Vilnius Gediminas Technical University. Dept of Geodesy and Cadastre, Sauletekio al. 11, LT-10223 Vilnius, Lithuania. $\mathrm{Ph}+3705274$ 4703, Fax +370 5274 4705,

e-mail: edita.alekniene@ap.vgtu.lt

A graduate of Vilnius Gediminas Technical University (Master of science 1998).

Co-author of a study guide and 3 research papers.

Research interests: investigation of geodynamic processes, GIS, investigations of deformations. 